\title{
Anti-Invasion and Antimetastatic Effects of Porcine Recombinant NK-lysin on SMMC-7721 Human Hepatocellular Carcinoma Cells
}

\author{
Kuohai Fan $\mathbb{D}^{1},{ }^{1}$ Wenjuan Du, ${ }^{2}$ Zhirui Wang, ${ }^{3}$ Ajab Khan, ${ }^{2}$ \\ Hongquan $\mathrm{Li}^{2}$, and Junbing Jiang $\mathbb{D}^{2}$ \\ ${ }^{1}$ Laboratory Animal Center, Shanxi Agricultural University, Taigu, Shanxi, China \\ ${ }^{2}$ College of Animal Science and Veterinary Medicine, Shanxi Agricultural University, Taigu, Shanxi, China \\ ${ }^{3}$ Plastic \& Reconstructive Surgery, University of Colorado Denver, Denver, CO, USA \\ Correspondence should be addressed to Junbing Jiang; sxndjeffrey@126.com
}

Received 12 January 2019; Revised 28 February 2019; Accepted 20 March 2019; Published 21 April 2019

Academic Editor: Ziad Fajloun

Copyright (C) 2019 Kuohai Fan et al. This is an open access article distributed under the Creative Commons Attribution License, which permits unrestricted use, distribution, and reproduction in any medium, provided the original work is properly cited.

The high invasion and metastasizing abilities of hepatocellular carcinoma (HCC) are the primary reasons for the high mortality rate of patients. Therefore, identification of agents to inhibit invasion and metastasis is very important for treatment of HCC. We analyzed the anti-invasion and antimetastatic effects of porcine recombinant NK-lysin, which was designed and expressed in vitro by our research group, on SMMC-7721 hepatocellular carcinoma cells via wound-healing assays, adhesion assays, invasion assays, real-time polymerase chain reaction (PCR), and Western blot analysis. MTT assay results indicated that NK-lysin inhibited the growth of SMMC-7721 cells in a dose- and time-dependent manner. NK-lysin reduced the ability of cell migration, adhesion, and invasion. Based on gene and protein expression analysis, NK-lysin decreased $\beta$-catenin and MMP-2 expression. These results suggested that NK-lysin has anti-invasion and antimetastatic effects on hepatocellular carcinoma cells in vitro by reducing the level of the $\beta$-catenin and MMP-2.

\section{Introduction}

Hepatocellular carcinoma (HCC) is one of the most common malignant tumors, accounting for about $80 \%$ of the cases worldwide [1]. The main treatment methods of HCC include hepatectomy, chemotherapy, and liver transplantation, but the ability to invade and metastasize leads to recurrence of HCC [2]. However, in the current anticancer therapeutic approaches, there is lack of the drugs that specifically target cancer invasion and metastasis [3]. Therefore identification of agents that cause inhibition of local invasion and metastasis is new strategies for the treatment of HCC.

NK-lysin is effector protein peptides that is secreted by natural killer (NK) cells and cytotoxic T lymphocytes (CTLs). In 1995, Andersson first separated and purified NKlysin from swine intestine [4]. Previous studies demonstrated that NK-lysin is an effective cationic antibacterial peptide that exhibits antibacterial properties and kills cancer cells without harming red cells $[4,5]$. At present, our group has successfully developed a eukaryotic expression system of the recombinant NK-lysin in vitro and demonstrated that it can inhibit the proliferation of hepatocellular carcinoma cells [6]. However, it remains unclear whether the recombinant NK-lysin exerts anti-invasive and antimetastatic activities.

The purpose of the present study was to determine the potential molecular mechanisms of anti-invasion and antimetastatic effects of NK-lysin on HCC in vitro. Our results provide a basis for the future development of NK-lysin as an anticancer agent, which may contribute to developing new antineoplastic medicines.

\section{Materials and Methods}

2.1. Cell Line. The HCC cell line SMMC-7721 was purchased from the Cell Bank of Shanghai Chinese Academy of Sciences (Shanghai, China). 
2.2. NK-lysin Preparation. The recombinant porcine NKlysin was expressed using the Pichia pastoris system by our laboratory [6]. NK-lysin was dissolved in phosphate buffered saline (PBS). The solution was filtered through a $0.22-\mu \mathrm{m}$ filter and stored at $-20^{\circ} \mathrm{C}$.

2.3. Cell Proliferation Assay. SMMC-7721 cells in mid-log phase were seeded in a 96-well plate at a density of $4 \times 10^{4}$ cells/well in $100 \mu \mathrm{L}$ of medium (Thermo Fisher Scientific, Waltham, USA) and incubated at $37^{\circ} \mathrm{C}$ and $5 \% \mathrm{CO}_{2}$ for 24 hrs. The supernatant was discarded, and cells were treated with a series of NK-lysin concentrations (320, 160, 80, 40, $20,10,5$, and $2.5 \mu \mathrm{g} / \mathrm{mL}$ ) for 24,48 , and 72 hrs using PBS as a control. The inhibition effect of NK-lysin on SMMC7721 cells was analyzed using the MTT assay (Amresco, USA). After 24, 48, and $72 \mathrm{hrs}$, the supernatant was discarded, and 20 $\mu \mathrm{L}$ of $5 \mathrm{mg} / \mathrm{mL}$ MTT was added to every well and incubated at $37^{\circ} \mathrm{C}$ for $4 \mathrm{hrs}$. The supernatant was discarded, and 150 $\mu \mathrm{L}$ of DMSO (Solarbio, Beijing, China) was added to each well. The cells were incubated at $37^{\circ} \mathrm{C}$ for $20 \mathrm{~min}$ until the precipitate was completely dissolved. The spectrophotometric absorbance was measured using the microplate reader (ELx808; Gene Co., Ltd., Hong Kong, China) at 490 and $630 \mathrm{~nm}$ (absorbance $490 \mathrm{~nm}$ and reference $630 \mathrm{~nm}$ ). Each independent experiment was performed in triplicate. The inhibition rate of cell proliferation (IR) was calculated as follows: IR = [1 - (OD490 nm- OD630 nm) treated $/(O D 490$ $\mathrm{nm}-\mathrm{OD} 630 \mathrm{~nm})$ nontreated control] $\times 100 \%$.

2.4. Cell Wound-Healing Assay. The wound-healing assay was used to evaluate the cancer cell migration capability in $2 \mathrm{D}$ space. SMMC-7721 cells at mid-log phase were seeded in a 12-well plate at a density of $4 \times 10^{5}$ cells/well in $1 \mathrm{~mL}$ of medium, and they were incubated at $37^{\circ} \mathrm{C}$ and $5 \% \mathrm{CO}_{2}$ for 24 hrs. A scratch was made (along the width of the well) using 1-10 $\mu \mathrm{L}$ sterile pipette tip. The supernatant was discarded and the cells were washed twice with PBS. The cells were then treated with various concentrations of NK-lysin $(40,20$, and $10 \mu \mathrm{g} / \mathrm{mL}$ ) for $24 \mathrm{hrs}$ and PBS was used as a control. The migrated distance was measured by Image J. Each independent experiment was performed in triplicate. The inhibition rate of cell migration (IR) was calculated as follows: $\mathrm{IR}=[$ (transport width of nontreated control-transport width of the experimental group migration)/transport width of nontreated control] $\times 100 \%$.

2.5. Cell Adhesion Assay. A 96-well plate was coated with Matrigel (Corning Incorporated, New York, NY, USA) and incubated overnight. SMMC-7721 cells at mid-log phase were seeded in a 6-well plate at a density of $8 \times 10^{5}$ cells/well in $2 \mathrm{~mL}$ of medium, and the cells were incubated at $37^{\circ} \mathrm{C}$ and $5 \% \mathrm{CO}_{2}$ for $24 \mathrm{hrs}$. The supernatant was discarded, and the cells were treated with a series of NK-lysin concentrations $(40,20$, and $10 \mu \mathrm{g} / \mathrm{mL})$ for $24 \mathrm{hrs}$ and PBS was used as a control. After treatment, the cells were collected and seeded in a 96-well plate at a density of $2 \times 10^{4}$ cells/well in $100 \mu \mathrm{L}$ medium and incubated at $37^{\circ} \mathrm{C}$ and $5 \% \mathrm{CO}_{2}$ for $2 \mathrm{hrs}$. The supernatant was discarded and $20 \mu \mathrm{L}$ of $5 \mathrm{mg} / \mathrm{mL}$ MTT was then added to every well. The cells were incubated at $37^{\circ} \mathrm{C}$ for $4 \mathrm{hrs}$, supernatant was discarded, and $150 \mu \mathrm{L}$ DMSO was added to each well, incubated at $37^{\circ} \mathrm{C}$ for $20 \mathrm{~min}$ until the precipitate was completely dissolved. The spectrophotometric absorbance at $570 \mathrm{~nm}$ was measured using the microplate reader. Each independent experiment was performed in triplicate. The inhibition rate of cell adhesion (IR) was calculated as follows: $\mathrm{IR}=[$ (nontreated control OD value-experimental group OD value)/nontreated control OD value] $\times 100 \%$.

2.6. Cell Transwell Assay. Invasion assays were used to investigate cancer cell migration in three-dimensional (3D) gels. The transwell upper chamber was coated with Matrigel and incubated at $37^{\circ} \mathrm{C}$ and $5 \% \mathrm{CO}_{2}$ for $2 \mathrm{hrs}$. The SMMC-7721 cells were washed once with PBS and serum-free medium was added and then grown at $37^{\circ} \mathrm{C}$ and $5 \% \mathrm{CO}_{2}$ for 12 hrs. Cells were collected and seeded in the transwell upper chamber $(8.0 \mu \mathrm{m} / 6.5 \mathrm{~mm}$; Corning Incorporated, New York, NY, USA) at a density of $2 \times 10^{4}$ cells/well in $200 \mu \mathrm{L}$ of medium containing various concentrations of NK-lysin (40, 20 , and $10 \mu \mathrm{g} / \mathrm{mL}$ ) and PBS. The bottom chambers were filled with culture medium containing $20 \%$ fetal bovine serum (FBS). After incubation for $24 \mathrm{hrs}$, the cells on the upper surface of the well were removed, and the cells on the lower surface were fixed with cold methanol and stained with $0.4 \%$ crystal violet. For each experiment, the number of transmigrated cells in five random fields on the underside of the filter was counted and photographed. Each independent experiment was performed in triplicate. The inhibition rate of cell invasion (IR) was calculated as follows: IR $=[$ (number of nontreated control invasive cell-number of the experimental group invasive cell)/number of nontreated control invasive cell] $\times 100 \%$.

\subsection{Real-Time Quantitative Polymerase Chain Reaction} ( $q$ PCR) Assay. Total RNA was extracted using TRIzol reagent (Invitrogen, USA) according to the manufacturer's instructions. Purified RNA with an A260/A280 ratio of 1.8 to 2.0 was used. Total RNA $(1 \mu \mathrm{g})$ was used for cDNA synthesis with random hexamer primers using a Prime Script RT reagent kit with gDNA Eraser (TaKaRa Bio, Co, Ltd, Dalian, China). qPCR was performed on 7500 Real Time PCR System (Life Technologies, USA) using the QuantiTect SYBR Green PCR kit (QIAGEN, Hilden, Germany) according to the manufacturer's instructions. The detected genes included MMP2 (Accession number: NM_004530.5, F: TGATCTTGACCAGAATACCATCGA; R: GGCTTGCGAGGGAAGAAGTT) and $\beta$-catenin (Accession number: X87838, F: ACCTTTCCCATCATCGTGAG; R: GCTTTGGTTCACCAGTGGATT). The data were then normalized to the expression of $\beta$-actin (Accession number: NC_018913.2, F: AAATCGTGCGTGACATTAA; R: GGAAGGAAGGTTGGAAGAGAGC) mRNA. The PCR cycling conditions were as follows: $95^{\circ} \mathrm{C}$ for $5 \mathrm{~min}$ followed by $40 \mathrm{cycles}$ of $95^{\circ} \mathrm{C}$ for $10 \mathrm{~s}, 60^{\circ} \mathrm{C}$ for $30 \mathrm{~s}$, and $72^{\circ} \mathrm{C}$ for $6 \mathrm{~s}$. Based on the melting curve analysis, the PCR product was demonstrated to be specific. The expression level of the target gene was compared with the control group, and the 
results were calculated using the 2- $\Delta \Delta \mathrm{Ct}$ method. Each RNA sample was measured in duplicate.

2.8. Western Blot Assay. The cells were lysed in $500 \mu \mathrm{L}$ of lysis buffer (APPLY GEN, Beijing, China) per well for $2 \mathrm{~min}$ on ice, and the lysates were collected in 1.5-mL centrifuge tubes. The lysates was added to $500 \mu \mathrm{L}$ of extraction buffer for $10 \mathrm{~min}$ on ice followed by centrifugation at $10000 \times \mathrm{g}$ for $20 \mathrm{~min}$ at $4^{\circ} \mathrm{C}$. The middle phases were harvested and $1 \mathrm{~mL}$ of ethanol was added and the sample was then centrifuged at $10000 \times \mathrm{g}$ for $3 \mathrm{~min}$ at $4^{\circ} \mathrm{C}$. The precipitate was collected and air-dried and $150 \mu \mathrm{L}$ of $2 \%$ sodium dodecyl sulfate (SDS) was added to dissolve the protein. The protein concentration was determined with a BCA Kit (BCA, Beyotime, Shanghai). Equal amounts of protein $(50 \mu \mathrm{g})$ were used for $8 \%$ sodium dodecyl sulfate-polyacrylamide gel electrophoresis (SDS-PAGE). Protein blots were transferred to polyvinylidene difluoride (PVDF) membranes (Millipore, Billerica, MA, USA). The membranes were blocked with $5 \%$ bovine serum albumin (BSA) in Tris-buffered saline with Tween20 (TBST) for 2 hrs and incubated with primary antibodies (Cell Signaling Technology, Inc., USA) overnight at $4^{\circ} \mathrm{C}$. The membranes were washed thrice with TBST (20\% Tween20) and incubated with the secondary antibodies (ComWin Biotech, Beijing, China) for $1 \mathrm{hr}$ at $37^{\circ} \mathrm{C}$ and then washed again thrice with TBST. Immunoreactive bands were detected by enhanced chemiluminescence (ECL) and visualized by exposure to Kodak X-ray film (Eastman Kodak, Rochester, NY, USA). The protein expression levels were compared with the control based on the relative intensities of the bands.

2.9. Statistical Analysis. All data were analyzed by oneway analysis of variance (ANOVA) followed by Dunnett's multiple comparison test and $\mathrm{P}<0.05$ was considered as statistically significant. The data were shown as means \pm SEM and analyzed using GraphPad Prism5 software (GraphPad Software, Inc., San Diego, CA).

\section{Results}

3.1. NK-lysin Inhibits SMMC-7721 Cell Proliferation. We tested the proliferative inhibition effect of NK-lysin on the SMMC-7721 cell line using the MTT assay at different treatment intervals. The cellular proliferative inhibition rate of $320 \mathrm{ug} / \mathrm{mL}$ of $\mathrm{NK}-$ lysin was $49 \%, 73 \%$, and $85 \%$ at 24 , 48 , and $72 \mathrm{hrs}$, respectively. This finding demonstrated that NK-lysin treatment significantly inhibited SMMC-7721 cell growth in both dose- and time-dependent manner at 24, 48 , and 72 hrs (Figure 1). In vitro the percentages of cancer cell survival need to reach $85 \%-90 \%$ for detecting invasion and metastasis. The inhibition rate of the cells was less than $16 \%$ when SMMC-7721 cells were treated for 72 hrs with concentrations of NK-lysin less than $40 \mu \mathrm{g} / \mathrm{mL}$. This result suggested that this concentration and time point were suitable for detecting invasion and metastasis. Thus, we used doses of 40,20 , and $10 \mu \mathrm{g} / \mathrm{mL}$ for the follow-up experiments.

3.2. Effect of NK-lysin on SMMC-7721 Cell Migration Ability. The migration ability of cancer cells is directly related with disease progression as higher migration rate results in reduced opportunities to heal cancer patients. We investigated the migration effects of NK-lysin on SMMC-7721 cells in vitro. The migration inhibition rates of NK-lysin-treated cells were $26.97 \pm 2.641 \%, 34.81 \pm 2.292 \%$, and $36.96 \pm 1.511 \%$ at 10,20 , and $40 \mu \mathrm{g} / \mathrm{mL}$, respectively, whereas the migration inhibition rate of PBS-treated cells was $4.265 \pm 0.8175 \%$. The migrated distance of NK-lysin-treated cells significantly decreased compared with the nontreated control (Figure 2(a)). The wound of nontreated control cells was almost closed, but the NK-lysin treated cells exhibited noticeable injury. Nevertheless, the migration inhibition rate did not change in the PBS-treated group compared to the nontreated control group (Figure 2(b)).

3.3. Effect of NK-lysin on the Adhesion Ability of SMMC-7721 Cells. We investigated the effects of NK-lysin on SMMC7721 cell adhesion in vitro because the adhesion ability of cancer cells has a direct positive correlation with invasion. The adhesion inhibition rates of NK-lysin-treated cells were $14.72 \pm 0.4838 \%, 34.73 \pm 0.9122 \%$, and $59.58 \pm 0.4159 \%$ at 10,20 , and $40 \mu \mathrm{g} / \mathrm{mL}$, respectively, whereas the adhesion inhibition rate of PBS-treated cells was 3.143 $\pm 3.201 \%$. The cell adhesion ability was significantly decreased in the NK-lysin-treated cells compared with nontreated control cells. However, the adhesion inhibition rate did not change in the PBS-treated group compared to the nontreated control group (Figure 3 ).

3.4. Invasion Ability Effect of NK-lysin on SMMC-7721 Cells. Invasion is a canonical feature of cancer cells, and it is a prerequisite for cancer metastasis. Therefore, we investigated the effects of NK-lysin on the invasion of SMMC-7721 cells in vitro (Figure $4(\mathrm{a})$ ). The invasion inhibition rates of NKlysin-treated cells were $19.71 \pm 4.267 \%, 41.31 \pm 0.6577 \%$, and $59.87 \pm 3.159 \%$ at 10,20 , and $40 \mu \mathrm{g} / \mathrm{mL}$ concentration of NKlysin, respectively, while the invasion inhibition rate of PBStreated cells was $8.650 \pm 1.526 \%$ compared with the nontreated control cells. The invasion ability was significantly decreased in the NK-lysin-treated groups compared with the nontreated control SMMC-7721 cells. However, the invasion inhibition rate ability did not changed in the PBS-treated group compared to the nontreated control group (Figure 4(b)).

3.5. Effect of NK-lysin on $\beta$-Catenin and MMP-2 Expression in SMMC-7721 Cells. The extracellular matrix (ECM) is degraded by matrix metalloproteinases (MMPs), which is an important step in cancer invasion and metastasis. MMP2 is a key member of the MMP family that can degrade the ECM. The present results showed that $\beta$-catenin and MMP-2 were highly expressed in cancer cells $[7,8]$. Thus, we investigated alterations of $\beta$-catenin and MMP- 2 expression in NK-lysin treated cells. $\beta$-catenin and MMP-2 mRNA expression levels were significantly decreased compared with nontreated control SMMC-7721 cells. However, the mRNA expression levels of $\beta$-catenin and MMP-2 did not change in the PBS-treated group compared to the nontreated control group (Figure 5). Western blot results were consistent with the mRNA expression levels (Figure 6). 

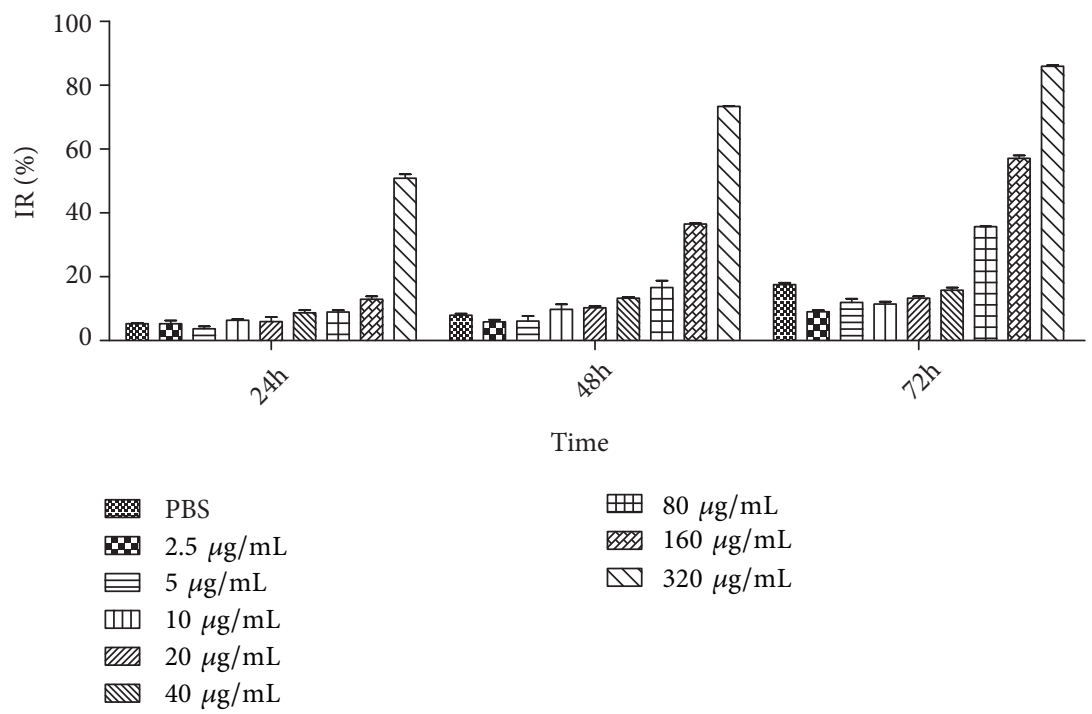

Figure 1: Proliferation inhibition effect of NK-lysin on SMMC-7721 cells $(n=3)$.
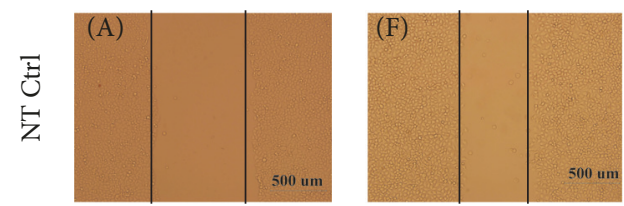

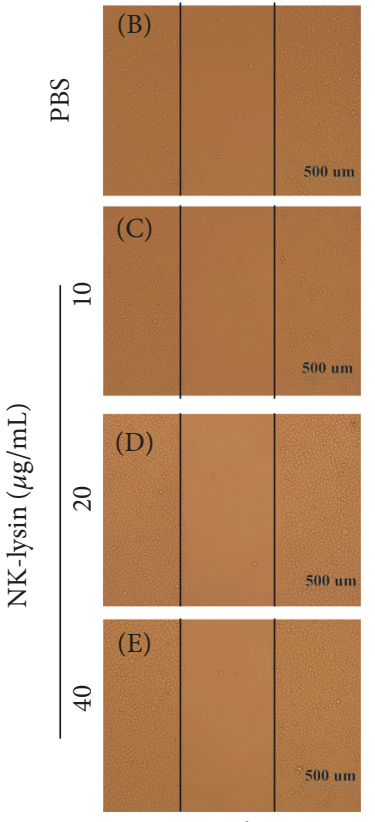

oh
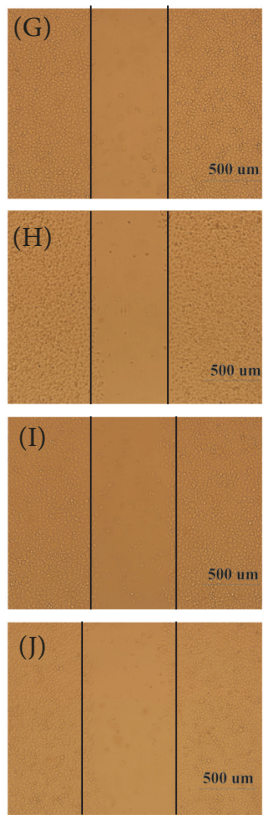

$24 \mathrm{~h}$

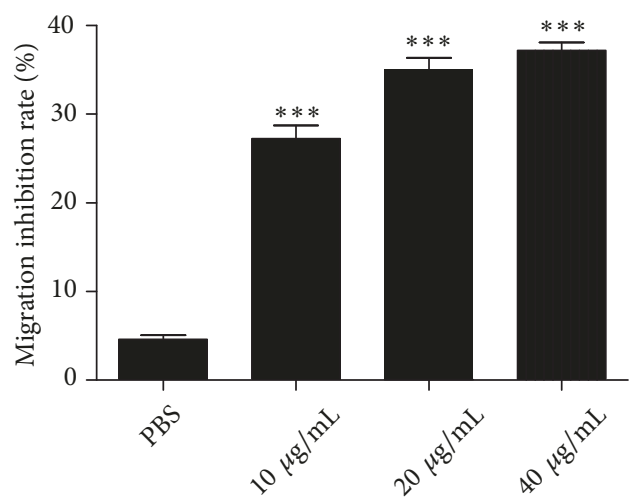

(b)

Figure 2: The effect of NK-lysin on SMMC-7721 cell migration. The scratch width of the different groups on SMMC-7721 cells after 24 hrs (a). Migration inhibition analysis of the various concentrations of NK-lysin and PBS (b). The migration inhibition rate of the NK-lysin group compared with the PBS group. The values are presented as the mean \pm SEM $(n=3), * * * P<0.001$ vs. the PBS group. 


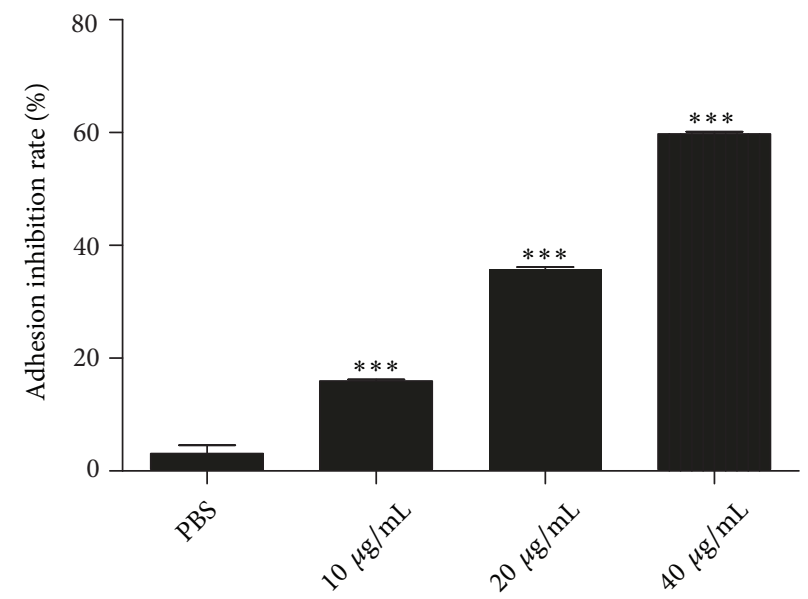

FIGURE 3: The adhesion inhibition analysis of the different concentrations of NK-lysin and PBS. Cells of various groups were incubated for 24 hrs. The adhesion inhibition rate of NK-lysin group significantly differed from the PBS group. The values are presented as the mean \pm SEM $(\mathrm{n}=3), * * * P<0.001$ vs. the PBS group.

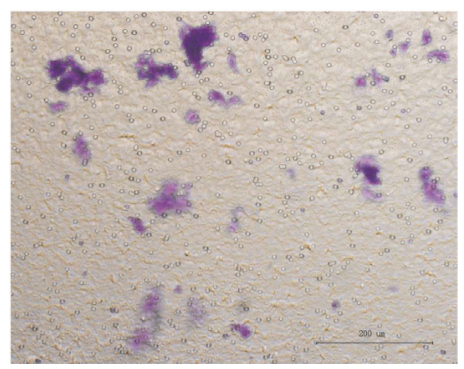

(A)

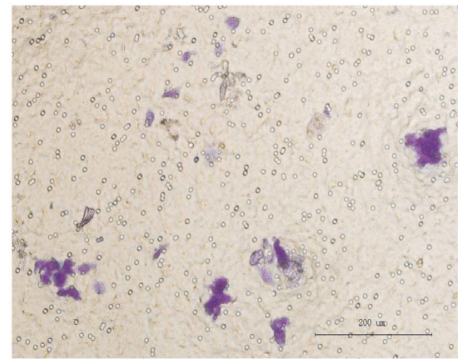

(B)

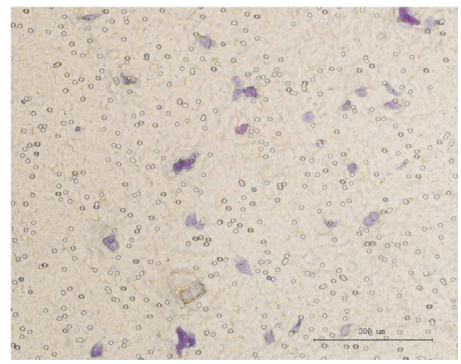

(C)

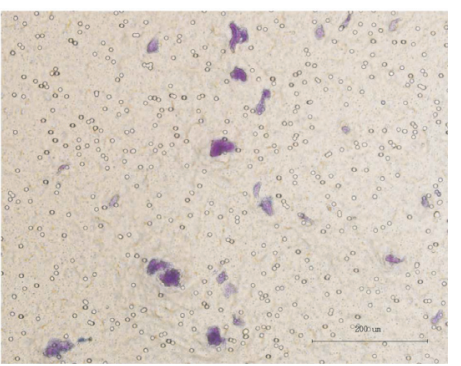

(D)

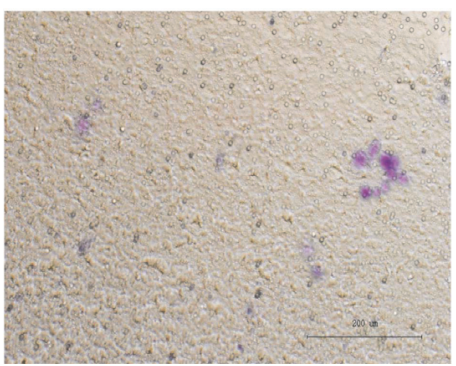

(E)

(a)

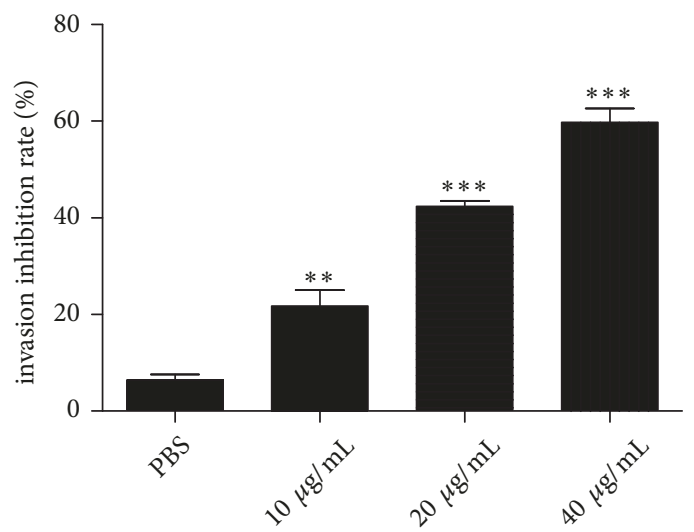

(b)

FIGURE 4: The invasion effect of NK-lysin on SMMC-7721 cells. Cells on the lower surface were fixed with cold methanol and stained with $0.4 \%$ crystal violet (a). (A): Nontreated control group, (B): PBS group, (C): $10 \mu \mathrm{g} / \mathrm{mL}$ NK-lysin group, (D): $20 \mu \mathrm{g} / \mathrm{mL}$ NK-lysin group, and (E): 40 $\mu \mathrm{g} / \mathrm{mL}$ NK-lysin group. The analysis of invasion inhibition rate of the different NK-lysin concentrations (b). The invasion inhibition rate of the NK-lysin group significantly differed from the PBS group. The values are presented as the mean \pm SEM $(\mathrm{n}=3), * * P<0.01, * * * P<0.001$ vs. the PBS group. 


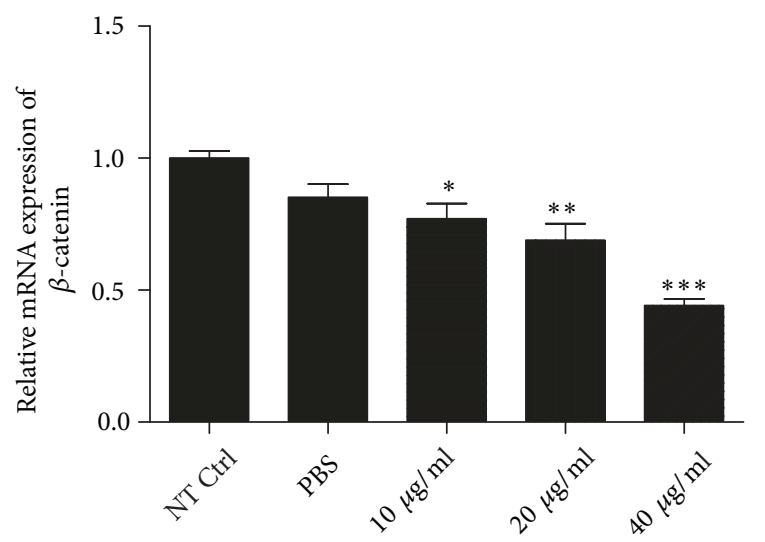

(a)

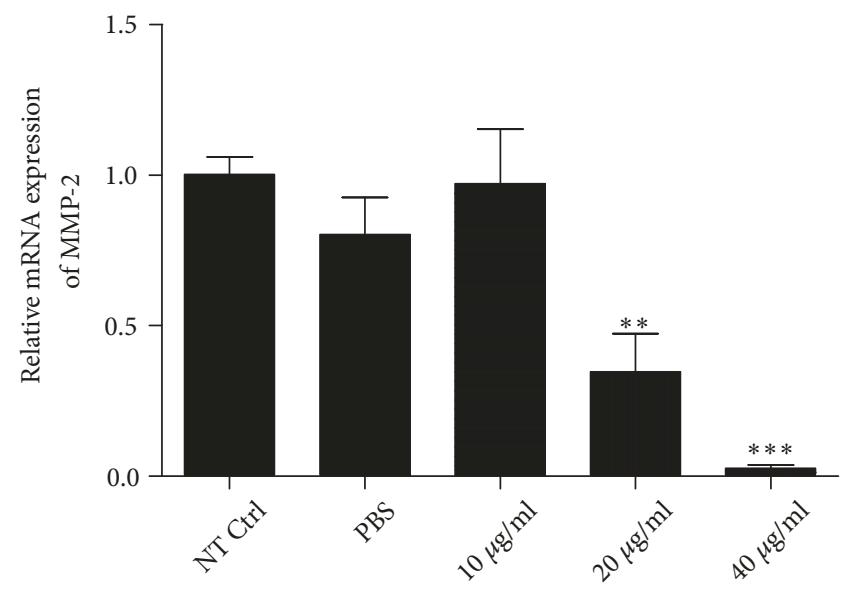

(b)

FIGURE 5: The effects of NK-lysin on relative mRNA expression levels in SMMC-7721 cells. Cells of different groups were incubated for 72 hrs, and qRT-PCR was used to evaluate mRNA expression levels. Relative mRNA expression of $\beta$-catenin (a) and MMP-2 (b). The values are presented as the mean \pm SEM $(\mathrm{n}=3), * P<0.05, * * P<0.01$, and $* * * P<0.001$ vs. the NT Ctrl group.

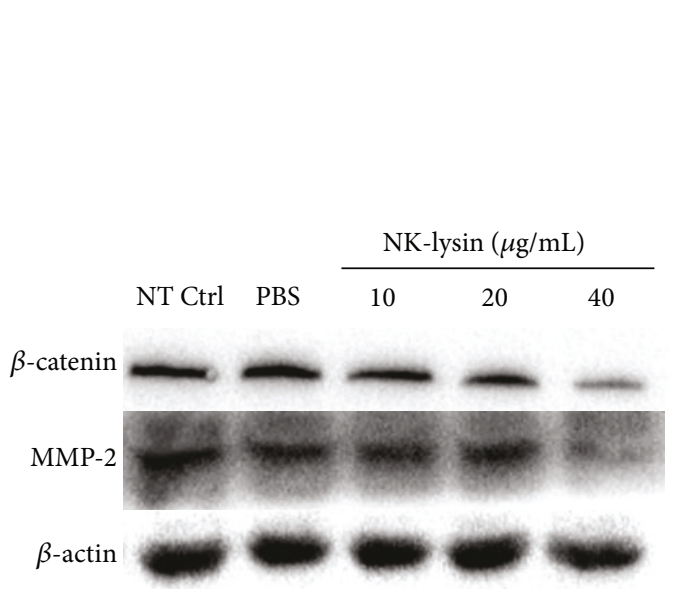

(a)

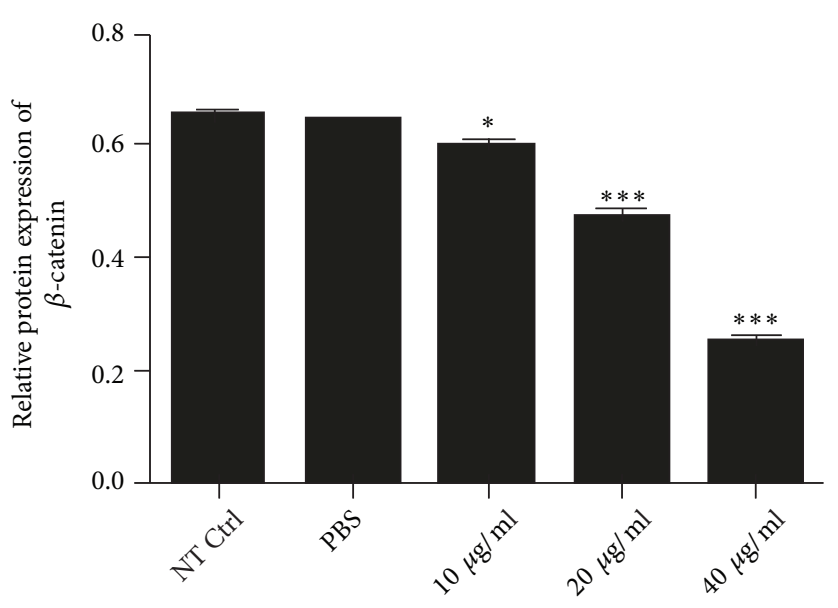

(b)

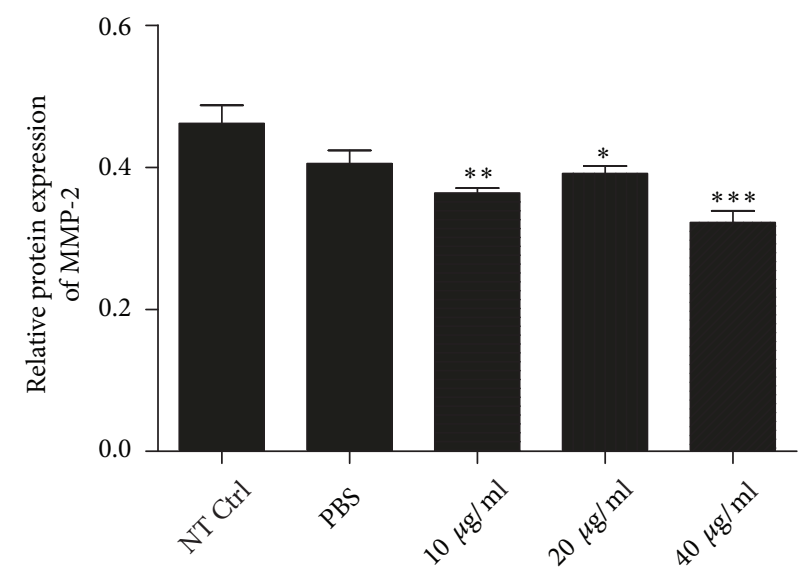

(c)

FIGURE 6: The effects of NK-lysin on protein expression levels in SMMC-7721 cells. Cells of different groups were incubated for 72 hrs, and Western blot analysis detected the levels of protein expression. $\beta$-actin was used as an internal control (a). Relative protein expression of $\beta$-catenin (b) and relative protein expression of MMP-2 (c). The values are presented as the mean \pm SEM $(n=3), * P<0.05, * * P<0.01$, and $* * * \mathrm{P}<0.001$ vs. NT Ctrl group. 


\section{Discussion}

Our previous study has found that NK-lysin suppressed the proliferation and reduced the filopodium formation of hepatocellular carcinoma [6]. The filopodium was considered to be related with the ability of cancer cells to metastasize [9]. Therefore, we examined the effects of NK-lysin on antiinvasion and antimetastasis with SMMC-7721 hepatocellular carcinoma. Firstly, the effects of NK-lysin on SMMC-7721 cells proliferation were tested by the MTT assay. The results indicated that NK-lysin inhibit the proliferation of SMMC7721 cells in concentration and time-dependent manner, and NK-lysin significantly decreased the migration of cells in wound-healing assay, the invasion ability of the SMMC-7721 cells in invasion assay, and adhesion ability of the SMMC7721 cells in cell adhesion assay. It indicates that NK-lysin can significantly inhibit the invasion and metastasis of HCC cells.

Aberrant activation of the $\mathrm{Wnt} / \beta$-catenin signalling pathway has a close relationship with cancer initiation, progression, and metastasis [7, 10, 11]. Invasion and metastasis of HCC have been inhibited by decreasing Wnt/ $\beta$-catenin signaling $[12,13]$. MMPs, a very important proteolytic enzyme, are involved in the cancer cells invasion and metastasis $[8,14]$. MMPs efficiently degrade extracellular matrix components in tissue surrounding a tumor, which results in the entry and survival of cancer cells in the circulation, lymphatic, or peritoneal spaces, and arrest in a distant target organ $[2,15] . \beta$-catenin and MMP-2 play critical roles in cancer cell invasion and metastasis and these proteins are overexpressed in cancer. In this study, we demonstrated NK-lysin could significantly reduce $\beta$-catenin and MMP-2 expression of SMMC-7221 cells at the mRNA and protein levels. The results indicated that NK-lysin may inhibit HCC invasion and metastasis by suppressing the expression of $\beta$-catenin and MMP-2.

\section{Conclusions}

The present study indicated that NK-lysin has significant anti-invasion and antimetastasis effects on HCC cells. Further in-depth research will be performed because NKlysin is a potential candidate compound for HCC treatment to help develop new antimicrobial peptides as anticancer drugs.

\section{Data Availability}

The data used to support the findings of this study are available from the corresponding author upon request.

\section{Conflicts of Interest}

The authors declare that there are no conflicts of interest regarding the publication of this paper.

\section{Authors' Contributions}

Kuohai Fan and Wenjuan Du contributed equally to this work.

\section{Acknowledgments}

This work was supported by the Key Research and Development Plan of Shanxi Province (Grant no. 201603D211092) and the Shanxi Province Science Foundation for Youths (Grant no. 201701D221185).

\section{References}

[1] M. Abbastabar, M. Sarfi, A. Golestani, and E. Khalili, "Lncrna involvement in hepatocellular carcinoma metastasis and prognosis," EXCLI Journal, vol. 17, pp. 900-913, 2018.

[2] J. T. Lu, W. He, S. S. Song, and W. Wei, "Paeoniflorin inhibited the tumor invasion and metastasis in human hepatocellular carcinoma cells," Bratislava Medical Journal, vol. 115, no. 7, pp. 427-433, 2014.

[3] A. Gandalovičová, D. Rosel, M. Fernandes et al., "Migrastaticsanti-metastatic and anti-invasion drugs: promises and challenges," Trends in Cancer, vol. 3, no. 6, pp. 391-406, 2017.

[4] M. Andersson, H. Gunne, B. Agerberth et al., "NK-lysin, structure and function of a novel effector molecule of porcine T and NK cells," Veterinary Immunology and Immunopathology, vol. 54, no. 1-4, pp. 123-126, 1996.

[5] J. Yan, K. Wang, W. Dang et al., "Two hits are better than one: Membrane-active and DNA binding-related doubleaction mechanism of NK-18, a novel antimicrobial peptide derived from mammalian NK-lysin," Antimicrobial Agents and Chemotherapy, vol. 57, no. 1, pp. 220-228, 2013.

[6] K. Fan, H. Li, Z. Wang et al., "Expression and purification of the recombinant porcine NK-lysin in Pichia pastoris and observation of anticancer activity in vitro," Preparative Biochemistry and Biotechnology, vol. 46, no. 1, pp. 65-70, 2016.

[7] B. T. MacDonald, K. Tamai, and X. He, "Wnt/ $\beta$-catenin signaling: components, mechanisms, and diseases," Developmental Cell, vol. 17, no. 1, pp. 9-26, 2009.

[8] S. A. Aroner, B. A. Rosner, R. M. Tamimi et al., "Plasma matrix metalloproteinase 2 levels and breast cancer risk," Cancer Epidemiology, vol. 39, no. 3, pp. 321-327, 2015.

[9] G. Jacquemet, H. Baghirov, M. Georgiadou et al., "L-type calcium channels regulate filopodia stability and cancer cell invasion downstream of integrin signalling," Nature Communications, vol. 7, p. 13297, 2016.

[10] C. Yang, Y. Xu, F. Cheng et al., "miR-1301 inhibits hepatocellular carcinoma cell migration, invasion, and angiogenesis by decreasing Wnt/ $\beta$-catenin signaling through targeting BCL9," Cell Death \& Disease, vol. 8, no. 8, p. e2999, 2017.

[11] Y. Yang, J.-J. Yang, H. Tao, and W.-S. Jin, "New perspectives on $\beta$-catenin control of cell fate and proliferation in colon cancer," Food and Chemical Toxicology, vol. 74, pp. 14-19, 2014.

[12] F. H. Wang, X. J. Ma, D. Xu, and J. Luo, "UPK1B promotes the invasion and metastasis of bladder cancer via regulating the Wnt/ $\beta$-catenin pathway," European Review for Medical and Pharmacological Sciences, vol. 22, no. 17, pp. 5471-5480, 2018.

[13] Z. Yin, W. Xu, H. Xu, J. Zheng, and Y. Gu, "Overexpression of hdac6 suppresses tumor cell proliferation and metastasis by 
inhibition of the canonical Wnt/ $\beta$-catenin signaling pathway in hepatocellular carcinoma," Oncology Letters, vol. 16, no. 6, pp. 7082-7090, 2018.

[14] C. Sun, Z. Wang, Q. Zheng, and H. Zhang, "Salidroside inhibits migration and invasion of human fibrosarcoma HT1080 cells," Phytomedicine, vol. 19, no. 3-4, pp. 355-363, 2012.

[15] W.-T. Chang, C.-H. Chuang, W.-J. Lee, and C.-S. Huang, "Extract of Monascus purpureus CWT715 fermented from sorghum liquor biowaste inhibits migration and invasion of SKHep-1 human hepatocarcinoma cells," Molecules, vol. 21, no. 12, p. E1691, 2016. 


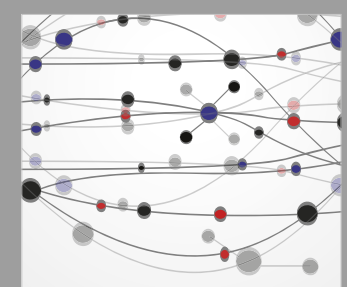

The Scientific World Journal
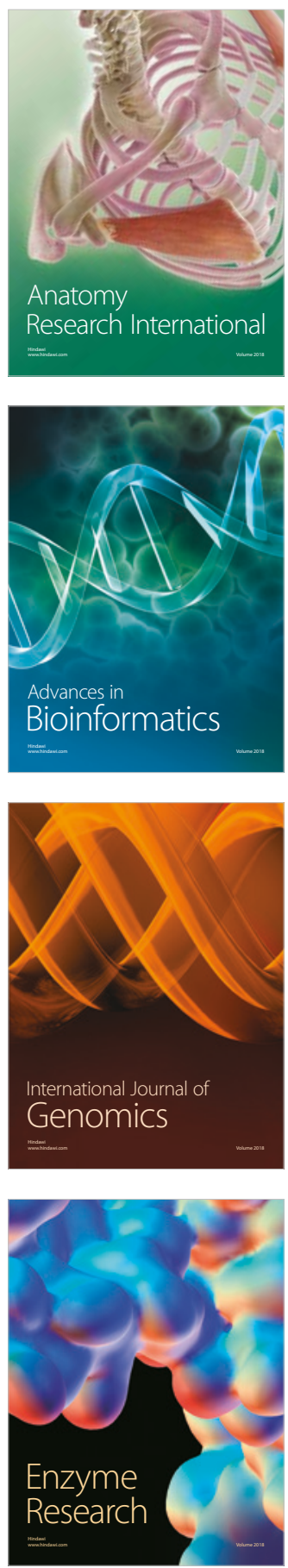
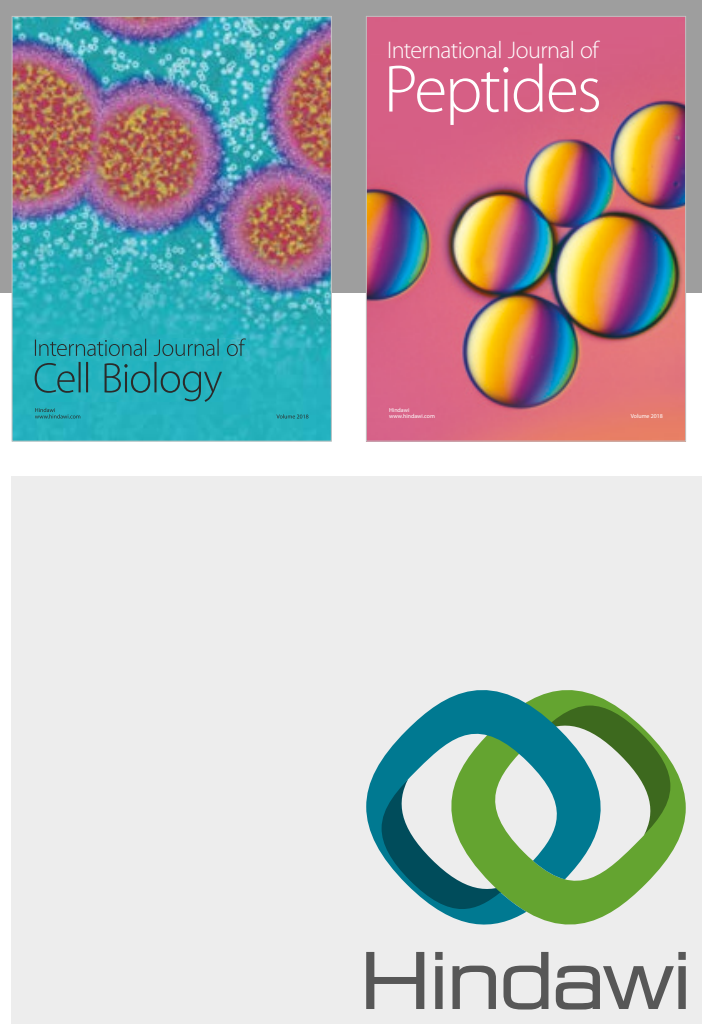

Submit your manuscripts at

www.hindawi.com
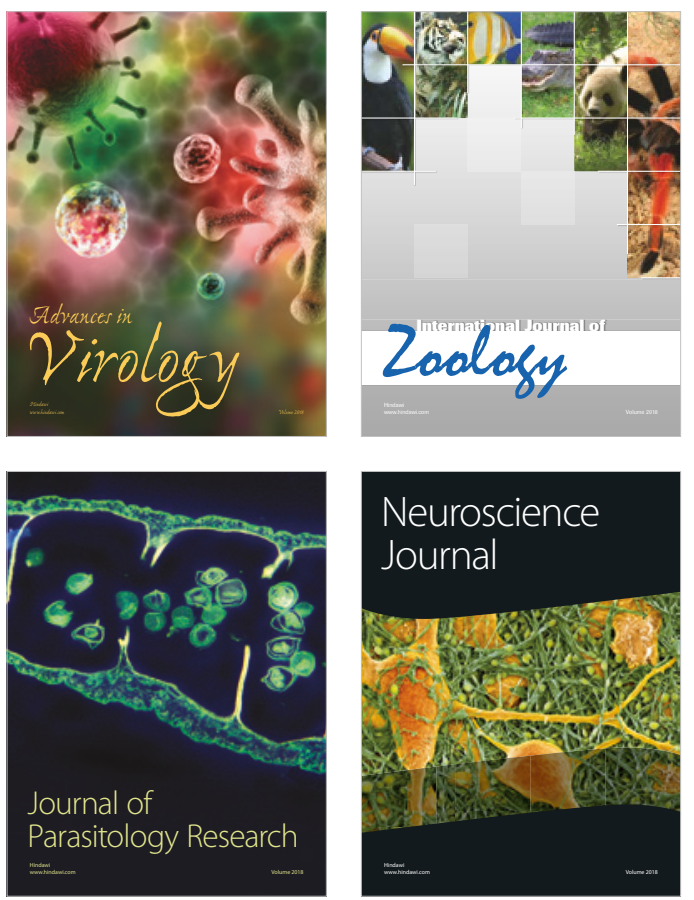
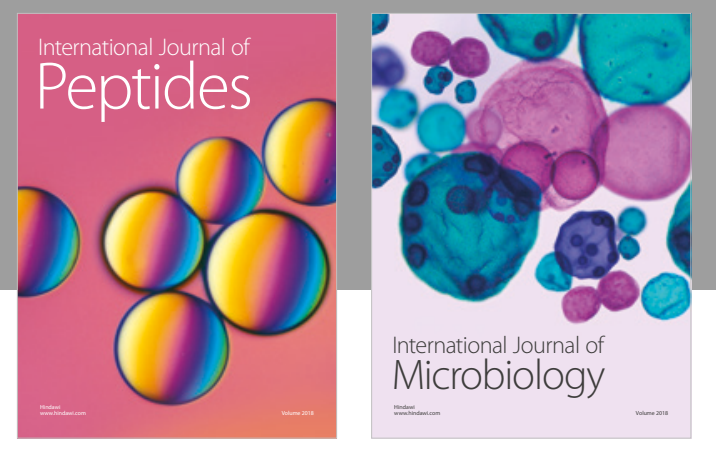

nternational Journal of Microbiology
Journal of
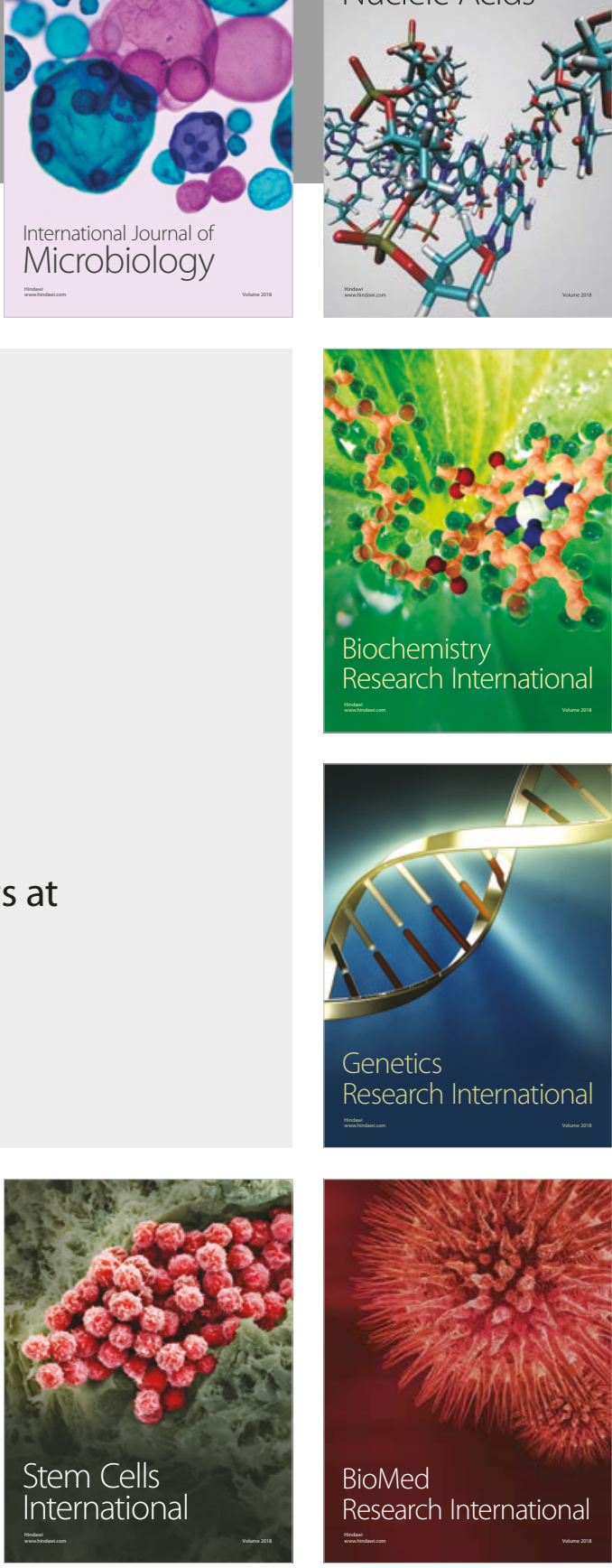
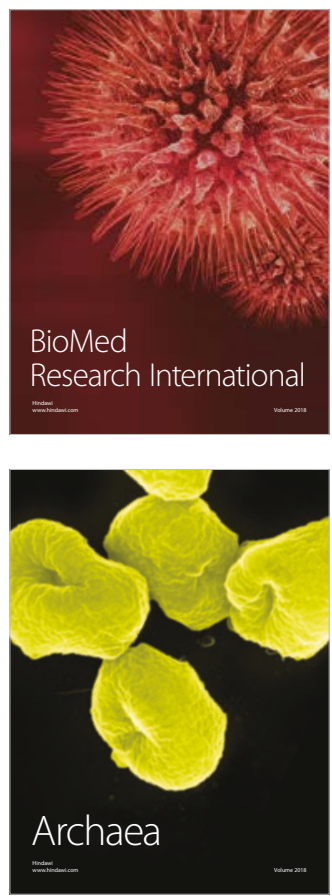